\title{
Metabolomic profile of the adrenal gland: from physiology to pathological conditions
}

\author{
Alessio Imperiale ${ }^{1,2}$, Karim Elbayed ${ }^{2}$, François-Marie Moussallieh ${ }^{1,2}$, Nathalie Reix ${ }^{2,3}$ \\ Martial Piotto ${ }^{2,4}$, Jean-Pierre Bellocq ${ }^{5}$, Bernard Goichot ${ }^{6}$, Philippe Bachellier $^{7}$ \\ and Izzie-Jacques Namer ${ }^{1,2}$ \\ 'Department of Biophysics and Nuclear Medicine, Strasbourg University Hospitals, Hôpital de Hautepierre, \\ 1, Avenue Molière, 67098 Strasbourg Cedex, France \\ ${ }^{2}$ ICube, University of Strasbourg/CNRS (UMR 7357), FMTS - Faculty of Medicine, Strasbourg, France \\ ${ }^{3}$ Laboratory of Hormonology, Strasbourg University Hospitals, Strasbourg, France \\ ${ }^{4}$ Bruker Biospin, Wissembourg, France \\ ${ }^{5}$ Department of Pathology, Strasbourg University Hospitals, Strasbourg, France \\ ${ }^{6}$ Department of Internal Medicine, Diabetes and Metabolic Disorders, Strasbourg University Hospitals, \\ Strasbourg, France \\ ${ }^{7}$ Department of Visceral Surgery and Transplantation, Strasbourg University Hospitals, Strasbourg, France
}

Correspondence should be addressed to A Imperiale Email

alessio.imperiale@ chru-strasbourg.fr

\begin{abstract}
In this study, we i) assessed the metabolic profile of the normal adrenal cortex and medulla of adult human subjects by means of ${ }^{1} \mathrm{H}$-high-resolution magic-angle spinning nuclear magnetic resonance (HRMAS NMR) spectroscopy; ii) compared the biochemical profile of adenoma (Ad), adrenal cortical carcinoma (ACC), and pheochromocytoma (PCC) samples with that of healthy adrenal tissue samples; and iii) investigated the metabolic differences between ACCs and Ads as well as between ACCs and PCCs. Sixty-six tissue samples (13 adrenal cortical tissue, eight medullary tissue, 13 Ad, 12 ACC, and 20 PCC samples) were analyzed. Adrenaline and noradrenaline were undetectable in cortical samples representing the metabolic signature of the tissue derived from neural crest. Similarity between the metabolic profile of Ads and that of the normal adrenal cortex was shown. Inversely, ACC samples clearly made up a detached group exhibiting the typical stigmata of neoplastic tissue such as choline-containing compounds, biochemical markers of anaerobic processes, and increased glycolysis. Significantly higher levels of lactate, acetate, and total choline-containing compounds played a major role in the differentiation of ACCs from Ads. Moreover, the high fatty acid content of ACCs contributed to the cluster identification of ACCs. Of the 14 sporadic PCC samples, 12 exhibited predominant or exclusive noradrenaline secretion. The noradrenaline: adrenaline ratio was inverted in the normal medullary tissue samples. Multiple endocrine neoplasia type 2- and NF1-related PCC samples exhibited both adrenaline and noradrenaline secretion. In the von Hippel-Lindau disease-related PCC samples, only noradrenaline secretion was detected by HRMAS NMR spectroscopy. This study is one of the first applications of metabolomics to adrenal pathophysiology and it is the largest study to report HRMAS NMR data related to the adrenal cortex and adrenal cortical tumors.
\end{abstract}

\author{
Key Words \\ - pheochromocytoma \\ - adrenal cortical carcinoma \\ - adrenal adenoma \\ - HRMAS \\ - metabolomics
}

Endocrine-Related Cancer (2013) 20, 705-716 http://erc.endocrinology-journals.org DOI: 10.1530/ERC-13-0232
(C) 2013 Society for Endocrinology Printed in Great Britain
Published by Bioscientifica Ltd 


\section{Introduction}

The adrenal gland is a fascinating organ with two functionally distinct structures called the adrenal cortex and medulla, each with its own embryonic origin. While the adrenal cortex derives from mesoderm, the adrenal medulla is composed of chromaffin cells originating from neural crest tissue.

Tumors originating from the adrenal cortex are commonly classified as functional or nonfunctional with a variable degree of malignancy. The most clinically relevant adrenocortical pathologies are adenomas (Ads) and adrenal cortical carcinomas (ACCs). While ACCs are relatively rare and extremely aggressive tumors, Ads are more frequently found and always benign. There is no evidence that Ads degenerate into malignant lesions (Young 2007, Lloyd 2011). The rarity of the disease and the presence of special variants (pediatric, oncocytic, myxoid, and sarcomatoid) complicate the pathological diagnosis of ACCs. Accurate discrimination between atypical adrenal cortical Ads and malignant ACCs in patients without gross evidence of malignancy can be difficult (Roman 2006). Nowadays, ACCs are being diagnosed based on the recognition of at least three of nine morphological parameters using light microscopy, according to the Weiss scoring system (Weiss et al. 1989, Papotti et al. 2011). Nevertheless, diagnostic accuracy could be reduced in borderline cases with only one or two Weiss criteria, particularly for nonexpert pathologists.

In adults, tumors originating from the adrenal medulla are mainly functional and called pheochromocytomas (PCCs). Although it is well established that the malignancy rate depends on the patient's genetic background, presently no marker of malignant potential is completely defined. The presence of metastases is indispensable to identify patients with malignant disease who require a more aggressive therapeutic approach. Finally, the combination of various clinical, biochemical, and/or histological markers can indicate an aggressive tumor behavior (Korevaar \& Grossman 2011).

Briefly, for both cortical and medullary neoplasms, the degree of malignancy is estimated according to the histological features clinical stage (particularly size) of the tumors and functional tests (McNicol 2011). Genetic and molecular alterations have been the subject of several studies, without, however, definitive conclusions being reached (Stratakis 2003, 2005, Lombardi et al. 2006).

${ }^{1} \mathrm{H}$-high-resolution magic-angle spinning nuclear magnetic resonance (HRMAS NMR) spectroscopy can characterize the metabolic phenotype of intact cells, tissues, and organs from the analysis of an intact tissue sample (Nicholson \& Wilson 2003). HRMAS NMR spectroscopy provides biochemical information related to the regulation of specific gene transcripts that are altered in the tumoral genome (Griffin \& Shockor 2004), generating great interest on the part of both the scientific and medical communities, particularly in oncology (Claudino et al. 2012, O'Connell 2012). At present, very limited data are available concerning the adrenal tissue. A few applications of HRMAS NMR spectroscopy to pediatric neuroblastomas have been described in the literature (Peet et al. 2007, Wilson et al. 2009, Imperiale et al. 2011). More recently, Timmers' team has reported an in vitro ${ }^{1} \mathrm{H}-\mathrm{NMR}$ spectroscopic study exploring the genotype-specific abnormalities in mitochondrial function associated with distinct profiles of energy metabolism and catecholamine content in PCCs and paragangliomas (Rao et al. 2013). To date, to the best of our knowledge, no other HRMAS NMR investigations concerning healthy adrenal tissue and the related pathologies have been reported, particularly regarding the adrenal cortex.

In this study, we first assessed the metabolic profile of both normal adrenal cortex and medulla of adult human subjects using HRMAS NMR spectroscopy. Then, we compared the biochemical pattern of healthy tissue with the profiles obtained from the Ad, ACC, and PCC samples. Finally, we investigated the differences between ACCs and Ads as well as between ACCs and PCCs.

\section{Subjects and methods}

\section{Tissue samples analyzed}

Among all the adrenal specimens collected in the tumor bank of the Strasbourg University Hospital until January 2010, 66 tissue samples including normal adrenal cortical and medullary tissue, Ad, ACC, and PCC samples were retrospectively selected for this study according to the following criteria: i) final diagnosis according to the pathological standards; ii) absence of both medical and surgical treatment before obtaining the tumor sample for HRMAS analysis; iii) tissue specimens collected after surgery and snap-frozen in liquid nitrogen before storage at $-80^{\circ} \mathrm{C}$; and iv) tissue samples not contaminated by the histopathological fixing medium.

Of the 66 tissue specimens analyzed, 13 normal adrenal cortical and eight normal medullary tissue samples were obtained from subjects who underwent

Published by Bioscientifica Ltd. 
both nephrectomy and adrenalectomy for localized and early-stage renal cell carcinoma. The other 45 tissue samples included $13 \mathrm{Ad}, 12 \mathrm{ACC}$, and 20 PCC samples.

In the Ad group, four samples were aldosteronesecreting Ads. No hormonal hypersecretion was associated with the remaining nine cases. The mean size of Ads determined during pathological examination was $3.3 \mathrm{~cm}$ (range $1.5-6 \mathrm{~cm}$ ). The mean age of the patients during adrenal surgery was 53 years (range $43-76$ years).

In the ACC group, six of the 12 samples were secreting tumors. The mean size of ACCs determined during pathological examination was $12 \mathrm{~cm}$ (range 6-24 cm). In all the cases, the Weiss score was $\geq 4$. Seven patients exhibited a locoregional involvement associated with nodal metastases. In the remaining five cases, ACC was confined to the adrenal gland at the time of surgery. Of these, three patients exhibited a systemic metastatic spread about 1 year later and two patients were free of disease during the first 5 years of postsurgical follow-up. The mean age of the patients during adrenal surgery was 62 years (range $32-80$ years).

Finally, in the PCC group, all the 20 samples were secreting tumors. In 14 of the 20 patients, no somatic mutation associated with multiple endocrine neoplasia type 2 (MEN2) and von Hippel-Lindau (VHL) disease was identified at the time of diagnosis. Moreover, no mutations in any of the succinate dehydrogenase complex subunit genes were identified in these patients. No case had a positive family history of nonsyndromic PCCs or paragangliomas. Hence, PCCs were considered as sporadic in 14 cases. On the other hand, PCCs were associated with MEN2 in two patients, Recklinghausen's disease (NF1) in two patients, and VHL disease in the remaining two cases. In all the 20 included patients, no metastatic spread was observed both at diagnosis and during a follow-up of at least 5 years after surgery. The mean size of the PCCs determined during pathological examination was $6.2 \mathrm{~cm}$ (range 1.5-14 cm). The mean age of the patients during adrenal surgery was 36 years (range 29-63 years). The tumor secretion profile was determined according to the results of the presurgical biochemical tests for plasma free metanephrines and/or urinary fractionated metanephrines and catecholamines.

\section{Tissue sample preparation for HRMAS NMR spectroscopy}

The amount of tissue used for the HRMAS analysis ranged from 15 to $20 \mathrm{mg}$. For each sample, the percentage of tumor cells and the percentage of necrosis with regard to the total surface were calculated based on frozen sections using a mirror sample stored in the tissue bank. Samples containing at least 30\% tumor cells and $<50 \%$ necrosis were used for this study. Each tissue sample was introduced into a $30 \mu \mathrm{l}$ disposable insert. Ten microliters of $\mathrm{D}_{2} \mathrm{O}$ were added to the rotor to provide a lock frequency for the NMR spectrometer. The exact weight of the sample used was determined by weighing the empty insert and the insert containing the tissue sample. The insert was stored at $-80{ }^{\circ} \mathrm{C}$ and placed in a $4 \mathrm{~mm} \mathrm{ZrO}_{2}$ rotor just before the HRMAS analysis.

\section{HRMAS NMR spectroscopy technical features}

HRMAS NMR spectra were recorded on a Bruker Advance III 500 spectrometer operating at a proton frequency of $500.13 \mathrm{MHz}$ and equipped with a $4 \mathrm{~mm}$ double-resonance $\left({ }^{1} \mathrm{H}\right.$ and $\left.{ }^{13} \mathrm{C}\right)$ gradient HRMAS probe. A Bruker cooling unit was used to regulate the temperature by cooling down the bearing air flowing into the probe. To minimize the effects of tissue degradation, all ex vivo spectra were acquired at a temperature of $4{ }^{\circ} \mathrm{C}$. This value was calibrated exactly using a $100 \%$ methanol sample. To keep the rotation sidebands out of the spectral region of interest and to minimize sample degradation, all NMR experiments were conducted on samples spinning at $3502 \mathrm{~Hz}$. For each sample, a one-dimensional (1D) proton spectrum using a Carr-Purcell-Meiboom-Gill (CPMG) pulse sequence with presaturation of the water signal was acquired as reported previously (Piotto et al. 2009). To eliminate signal losses due to $B_{1}$ inhomogeneity, the inter-pulse delay between the $180^{\circ}$ pulses of the CPMG pulse train was synchronized with the sample and set to $285 \mu$ s (Piotto et al. 2001, Elbayed et al. 2005). The number of loops was set to 328, thus giving the CPMG pulse train a total length of $93 \mathrm{~ms}$. The parameters for the CPMG experiment were set as follows: sweep width, 14.2 p.p.m.; number of points, 32k; relaxation delay, $2 \mathrm{~s}$; and acquisition time, $2.3 \mathrm{~s}$. A total of 128 free induction decays were acquired, resulting in an acquisition time of $10 \mathrm{~min}$. Spectra were referenced by setting the lactate doublet chemical shift to 1.33 p.p.m. In order to confirm resonance assignments, 2D homonuclear and heteronuclear experiments were also carried out immediately after the acquisition of 1D spectra. Because the duration of these experiments was long, they were conducted on only a few samples representative of each class of tissues and exclusively for signal assignment. Significant tissue degradation occurs during this long measurement time; therefore, ${ }^{1} \mathrm{H}$ CPMG experiments were completed before the $2 \mathrm{D}$ signal assignment experiments. Data were zero-filled to a $2 \mathrm{k} \times 1 \mathrm{k}$ matrix and

Published by Bioscientifica Ltd. 
weighted with a shifted square sine-bell function before Fourier transformation. HRMAS NMR signals were bucketed into integral regions 0.01 p.p.m. wide (p.p.m. range 8.65-1) using the AMIX 3.8 Software (Bruker $\mathrm{GmbH}$, Rheinstetten, Germany) and exported into SIMCA $\mathrm{P}$ (version 11.0, Umetrics $\mathrm{AB}$, Umeå, Sweden). To accommodate the influence of metabolites present at both high and low concentrations, without emphasizing spectral noise, unit variance scaling was employed for all the analyses. Spectra were referenced for chemical shift according to the lactate peak.

\section{Metabolite quantification procedure}

Metabolites were quantified by means of a proprietary program based on a custom MATLAB algorithm in a Windows-based environment. The quantification procedure was based on the pulse length-based concentration measurement (PULCON) described previously by our team (Piotto et al. 2012). Spectra were normalized according to the weight of each sample and calibrated using the signal intensity of a $19.3 \mathrm{nmol}$ reference solution of lactate, scanned under the same analytical conditions. The peak integral corresponding to each metabolite's region was normalized to the integral of the entire spectrum. For our experiments, only peaks that were well resolved in the 1D CPMG spectra were quantified. One pulse sequence was acquired in addition to the CPMG sequence for fatty acid (FA) estimation. Quantification results are expressed as nanomoles per milligram of tissue. Metabolites were assigned using standard metabolite chemical shift tables available in the literature (MartinezBisbal et al. 2004, Wishart et al. 2007).

To assess adrenaline concentrations in the tissue samples, the signal resulting from the $\mathrm{N}$-methyl radical selected at 2.75 p.p.m. was considered. The 3,4-dihydroxybenzene group of both adrenaline and noradrenaline generates a spectral complex between about 6.85 and 6.98 p.p.m. The integral of the region corresponding to the ${ }^{1} \mathrm{H}$ in position 5 of the aromatic ring (IUPAC nomenclature) was selected to quantify the amount of adrenaline plus noradrenaline in each tissue sample. Finally, noradrenaline concentrations were determined by subtracting adrenaline concentrations from adrenaline plus noradrenaline concentrations. A negative value of noradrenaline indicates that there was no physical quantity, so the 0 value was assigned to noradrenaline for the statistical analysis. Dopamine could contribute to peaks in the region between 6.85 and 6.98 p.p.m. However, no triplets at 2.85 and 3.22 p.p.m., representing the spectral signature of dopamine, were detected in HRMAS NMR spectra, suggesting the absence or an undetectable amount of dopamine in the analyzed tissue samples.

The above approach has been tested and confirmed (data not shown) previously using the quantification NMR analysis of adrenaline and noradrenaline standard solutions that were first separated and subsequently mixed $(1 / 1, v / v)$.

\section{Statistical analysis}

The standardized metabolite concentration values are expressed as median and range. As has been widely suggested (Sitter et al. 2009, Beckonert et al. 2010), a combination of principal component analysis (PCA) and partial least-squares discriminant analysis (PLS-DA) was employed.

A PCA was carried out to quickly evaluate the quality of the data and to identify possible outliers (Ebbels \& Cavill 2009). Then, a PLS-DA was employed to optimize the separation between groups in each of the following six models: i) normal adrenal cortex vs medulla; ii) normal adrenal cortex vs Ads; iii) normal adrenal cortex vs ACCs; iv) ACCs vs Ads; v) normal adrenal medulla vs PCCs; and vi) ACCs vs PCCs. PLS-DA was initially carried out for the whole set of variables (i.e. metabolites) in order to select those with a real discriminating power. These metabolites were determined using the regression coefficient plot with 95\% jackknifed CIs. Metabolites with a variable importance for projection (VIP) value $\geq 0.9$ were selected and labeled VIP metabolites. Afterwards, a second PLS-DA, based on the VIP metabolites, was carried out to classify the samples. Cross-validation was used in each PLS-DA model to determine the number of components and to avoid overfitting the data because of the small number of samples. Two measurements of model quality were reported for PLS-DA: $R^{2} Y$ and $Q^{2}$, representing respectively the goodness of fit (i.e. data variation) and the goodness of prediction, as estimated by cross-validation. A value of $Q^{2}$ $\geq 0.5$ is generally considered a good predictor for PLS-DA components. The relationships between variables were assessed using the Spearman's rank test. Comparisons were computed using the nonparametric Mann-Whitney $U$ test. The STATISTICA 7 (STATSOFT; www.statsoft.com) package was used for statistical data analysis. A $P$ value $<0.05$ was considered statistically significant.

\section{Results}

The representative 1D HRMAS CPMG spectra of the normal adrenal cortical and medullary tissue, Ad, ACC,

Published by Bioscientifica Ltd. 
and PCC samples are shown in Figs 1 and 2. A total of 24 identified metabolites were quantified from the spectra obtained from all the 66 tissue samples within the range of 8.65-1 p.p.m. (Table 1). Apart from peaks due to small water-soluble molecules, the acquired spectra displayed consistent broad resonances, which were attributed to three different FA moieties defined as a, b, and c (Martinez-Bisbal et al. 2004). Finally, five additional resolved signals that peaked at 1.14, 2.20, 3.36, 4.30, and 8.50 p.p.m. were visualized in the CPMG spectra without definitive metabolite attribution and therefore called $X_{1.14}, X_{2.20}, X_{3.36}, X_{4.30}$, and $X_{8.50}$.

\section{Normal adrenal cortex vs normal medulla}

Thirteen normal adrenal cortical and eight normal medullary tissue samples were included in the analysis. A two-component PLS-DA based on VIP metabolites was characterized by a faithful representation of the $Y$ data $\left(R^{2} Y=0.8\right)$ and a good cumulative confidence criterion of prediction $\left(Q^{2}=0.7\right)$. The score plot of the PLS-DA model showed a separation of the two sets of samples (Fig. 3). Normal medulla was characterized by a significantly higher abundance of adrenaline, noradrenaline, myoinositol, glutamate, glutathione, lactate, succinic and ascorbic acids, creatine, scyllo-inositol, glutamine, taurine, glycine, total choline-containing compounds, and $X_{4.30}, X_{3.36}$, and $X_{8.50}$. The adrenal cortex was characterized by a higher level of FA (a) and (b). Both adrenaline and noradrenaline complexes were undetectable in all the cortical samples.

\section{Normal adrenal cortex vs cortical Ads}

Thirteen normal adrenal cortical tissue and 13 Ad samples were considered. According to visual analysis, spectra belonging to adrenal cortical tissue and Ad samples were mostly related. The two-component PLS-DA model based on VIP metabolites showed only incomplete separation between the two sets of samples (Fig. 3) and was characterized by a low goodness-of-prediction value $\left(Q^{2}=0.4\right)$. Valine, alanine, aspartic acid, $\gamma$-aminobutyric
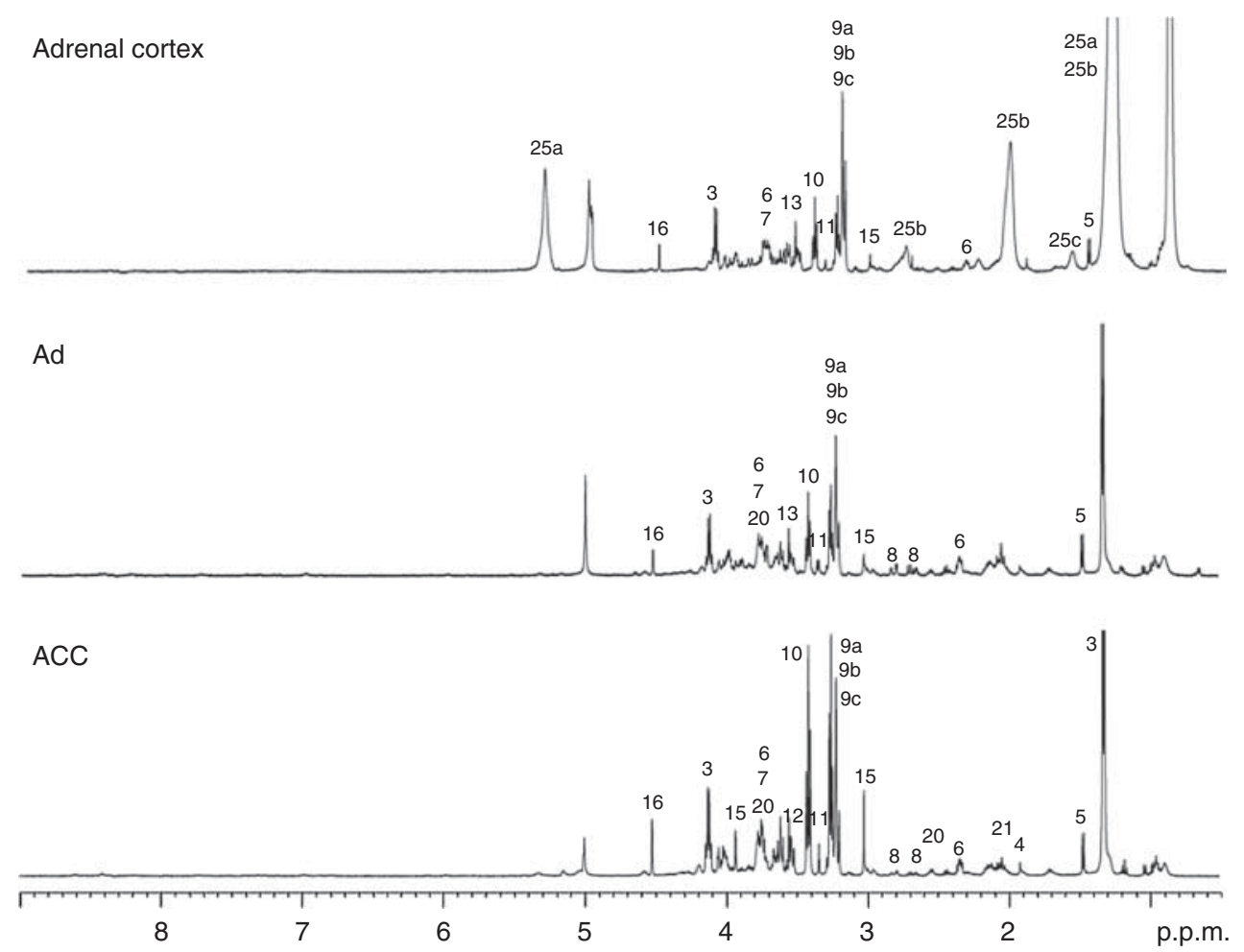

Figure 1

Representative 1D ${ }^{1} \mathrm{H}$ CPMG HRMAS spectra of healthy adrenal cortical tissue, Ad, and ACC samples. Partial metabolite assignment is indicated. The numbers refer to the metabolites listed in Table 1. The metabolic
(C) 2013 Society for Endocrinology
Printed in Great Britain content of healthy and cancerous tissues can be directly compared since the intensity of each spectrum was normalized with respect to the weight of the sample.

Published by Bioscientifica Ltd. 


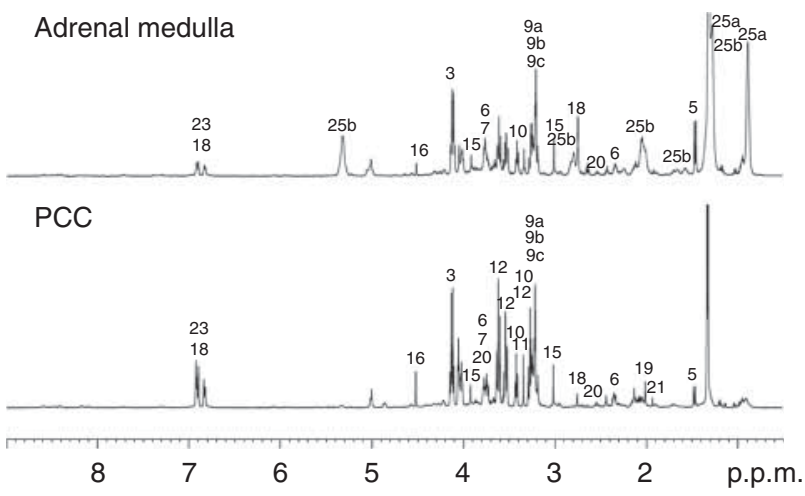

Figure 2

Representative 1D ${ }^{1} \mathrm{H}$ CPMG HRMAS spectra of both healthy adrenal medullary tissue and PCC samples. Partial metabolite assignment is indicated. The numbers refer to the metabolites listed in Table 1. The metabolic content of healthy and cancerous tissues can be directly compared since the intensity of each spectrum was normalized with respect to the weight of the sample.

acid (GABA), isoleucine, $\mathrm{N}$-acetyl aspartate (NAA), acetate, lysine, $X_{2.20}$, and FA (a), (b), and (c) were significantly more abundant in the cortical samples. Succinic acid and $X_{3.36}$ were slightly more abundant in Ad samples, without, however, reaching statistical significance.

A two-component PLS-DA model based on VIP metabolites was built from Ad samples according to hormonal secretion (Fig. 4A; $R^{2} Y=0.72$ and $Q^{2}=0.44$ ). scyllo-Inositol and $X_{3.36}$ and $X_{4.30}$ characterized nonsecreting Ad samples. On the other hand, glutamate, glutamine, GABA, $X_{2.20}$, and succinate were more abundant in secreting Ad samples. A statistically significant difference was found for $X_{3.36}$ and $X_{2.20}$, scylloinositol, GABA, and glutamate.

\section{Normal adrenal cortex vs ACCs}

Thirteen normal adrenal cortical tissue and 12 ACC samples were analyzed. The two tissue classes were clearly separated by a two-component PLS-DA based on VIP metabolites (Fig. 3), showing an accurate representation of the data and good cumulative confidence criterion of fit $\left(R^{2} Y=0.9\right)$ and prediction $\left(Q^{2}=0.85\right)$. The statistically significant abundance of glutathione, lactate, myoinositol, glycine, total choline-containing compounds, creatine, glutamate, glutamine, scyllo-inositol, and $X_{8.50}$ was found to be a discriminator of ACCs. The adrenal cortex was characterized by a higher level of NAA, isoleucine, FA (a) and (b), and $X_{4.30}$ and $X_{1.14}$. A twocomponent PLS-DA model based on VIP metabolites was built from ACC samples according to hormonal secretion (Fig. 4B; $R^{2} Y=0.71$ and $Q^{2}=0.44$ ). Glutamine, glutamate, acetate, lysine, valine, and succinate were more abundant in nonsecreting tumors, without reaching statistical significance. Secreting ACC samples exhibited a higher abundance of aspartate, FA (b), $X_{1.14}$, and total cholinecontaining compounds. However, no significant difference was observed for any of these metabolites.

Finally, when PLS-DA was built according to clinical aggressivity, the ten patients with metastatic ACCs were not successfully discriminated from the remaining two with confined disease at diagnosis and without systemic spread during the first 5 years of postsurgical follow-up.

\section{ACCs vs cortical Ads}

Twelve ACC and 13 Ad samples were included in the analysis. A two-component PLS-DA model based on VIP metabolites was characterized by $R^{2} Y=0.9$ and $Q^{2}=0.85$, showing a good differentiation of Ad and ACC samples (Fig. 3). A significantly higher abundance of lactate, GABA, creatine, NAA, acetate, alanine, glutamate, glutamine, valine, myo-inositol, glycine, glutathione, isoleucine, lysine, ethanolamine, FA, total choline-containing compounds, and $X_{2.20}$, and $X_{8.50}$ was found to be a discriminator of ACCs.

\section{Normal adrenal medulla vs PCCs}

Eight normal medullary tissue and 20 PCC samples were compared. When a two-component PLS-DA model was built using only data points corresponding to VIP metabolites, the following results were obtained: $R^{2} Y=0.8$ and $Q^{2}=0.7$. Figure 3 presents the score plot of the PLS-DA showing a clear separation between the two sets of samples. A significantly higher abundance of taurine, alanine, aspartate, GABA, glutathione, noradrenaline, ascorbic acid, total choline-containing compounds, and $X_{4.30}$ was observed in PCC samples than in the normal medullary tissue samples.

According to the presurgical biological evaluation, ten of the 14 sporadic PCC samples exhibited predominant noradrenaline secretion, two exclusive noradrenaline secretion and two predominant adrenaline secretion (Fig. 5). For all the examined sporadic PCC samples, HRMAS NMR spectroscopy revealed the presence of a greater amount of noradrenaline than of adrenaline. On the other hand, in the normal medullary tissue samples, adrenaline was more abundant than noradrenaline (Table 2). The abundance of noradrenaline was

Published by Bioscientifica Ltd 
Table $1{ }^{1} \mathrm{H}$-NMR resonance assignments of the metabolites identified and quantified in the 66 adrenal samples examined

\begin{tabular}{|c|c|c|c|}
\hline Numbers & Metabolite & Group & $\begin{array}{c}{ }^{\mathbf{1}} \text { chemical } \\
\text { shift } \\
\text { (p.p.m.) }\end{array}$ \\
\hline \multirow[t]{4}{*}{1} & \multirow[t]{4}{*}{ Isoleucine } & $\delta \mathrm{CH}_{3}$ & 0.94 \\
\hline & & $\gamma \mathrm{CH}_{3}$ & 1.01 \\
\hline & & $\gamma \mathrm{CH}_{2}$ & 1.51 \\
\hline & & $\alpha \mathrm{CH}$ & 3.65 \\
\hline \multirow[t]{3}{*}{2} & \multirow[t]{3}{*}{ Valine } & $\gamma \mathrm{CH}_{3}$ & 0.98 \\
\hline & & $\gamma^{\prime} \mathrm{CH}_{3}$ & 1.04 \\
\hline & & $\beta \mathrm{CH}$ & 2.30 \\
\hline \multirow[t]{2}{*}{3} & \multirow[t]{2}{*}{ Lactate } & $\mathrm{CH}_{3}$ & 1.33 \\
\hline & & $\mathrm{CH}$ & 4.12 \\
\hline \multirow[t]{4}{*}{4} & \multirow[t]{4}{*}{ Lysine } & $\gamma \mathrm{CH}_{2}$ & 1.43 \\
\hline & & $\delta \mathrm{CH}_{2}$ & 1.71 \\
\hline & & $\beta \mathrm{CH}_{2}$ & 1.89 \\
\hline & & $\varepsilon \mathrm{CH}_{2}$ & 3.01 \\
\hline \multirow[t]{2}{*}{5} & \multirow[t]{2}{*}{ Alanine } & $\mathrm{BCH}_{3}$ & 1.48 \\
\hline & & $\alpha \mathrm{CH}$ & 3.78 \\
\hline \multirow[t]{3}{*}{6} & \multirow[t]{3}{*}{ Glutamate } & $\beta \mathrm{CH}_{2}$ & 2.05 \\
\hline & & $\gamma \mathrm{CH}_{2}$ & 2.34 \\
\hline & & $\alpha \mathrm{CH}$ & 3.76 \\
\hline \multirow[t]{3}{*}{7} & \multirow[t]{3}{*}{ Glutamine } & $\beta \mathrm{CH}_{2}$ & 2.14 \\
\hline & & $\gamma \mathrm{CH}_{2}$ & 2.44 \\
\hline & & $\alpha \mathrm{CH}_{2}$ & 3.77 \\
\hline \multirow[t]{3}{*}{8} & \multirow[t]{3}{*}{ Aspartic acid } & $\beta \mathrm{CH}_{2}(\mathrm{u})$ & 2.70 \\
\hline & & $\beta \mathrm{CH}_{2}(\mathrm{~d})$ & 2.80 \\
\hline & & $\alpha \mathrm{CH}$ & 3.90 \\
\hline \multirow[t]{3}{*}{$9 a$} & \multirow[t]{3}{*}{ Choline } & $-\mathrm{N}^{+}-\left(\mathrm{CH}_{3}\right)_{3}$ & 3.21 \\
\hline & & $\beta \mathrm{CH}_{2}$ & 3.52 \\
\hline & & $\alpha \mathrm{CH}$ & 4.06 \\
\hline $9 b$ & Phosphorylcholine & $-\mathrm{N}^{+}-\left(\mathrm{CH}_{3}\right)_{3}$ & 3.22 \\
\hline & & $\mathrm{BCH}_{2}$ & 3.60 \\
\hline & & $\alpha \mathrm{CH}$ & 4.16 \\
\hline $9 c$ & Glycerophosphocholine & $-\mathrm{CH}_{2}-\mathrm{NH}_{3}{ }^{+}$ & 3.23 \\
\hline & & $\alpha \mathrm{CH}_{2}$ & 4.32 \\
\hline & & $\beta \mathrm{CH}_{2}$ & 3.69 \\
\hline & & $\mathrm{CH}_{2}-\mathrm{HPO}_{4}(\mathrm{~d})$ & 3.88 \\
\hline & & $\mathrm{CH}_{2} \mathrm{OH}$ & 3.91 \\
\hline & & $\mathrm{CH}_{2}-\mathrm{HPO}_{4}(\mathrm{u})$ & 3.95 \\
\hline 10 & Taurine & $-\mathrm{CH}_{2}-\mathrm{NH}_{3}{ }^{+}$ & 3.26 \\
\hline & & $-\mathrm{CH}_{2}-\mathrm{SO}_{3}^{-}$ & 3.42 \\
\hline 11 & scyllo-Inositol & All Hs & 3.35 \\
\hline 12 & myo-Inositol & $\mathrm{C} 5 \mathrm{H}$ & 3.27 \\
\hline & & $\mathrm{C} 1 \mathrm{H}, \mathrm{C} 3 \mathrm{H}$ & 3.54 \\
\hline & & $\mathrm{C} 4 \mathrm{H}, \mathrm{C} 6 \mathrm{H}$ & 3.61 \\
\hline & & $\mathrm{C} 2 \mathrm{H}$ & 4.06 \\
\hline 13 & Glycine & $\alpha \mathrm{CH}$ & 3.56 \\
\hline 14 & $\beta$-Glucose & $\mathrm{C} 4 \mathrm{H}$ & 3.43 \\
\hline & & $\mathrm{C} 3 \mathrm{H}, \mathrm{C} 5 \mathrm{H}$ & 3.47 \\
\hline & & $\mathrm{C} 6 \mathrm{H}(\mathrm{u})$ & 3.75 \\
\hline & & $\mathrm{C} 6 \mathrm{H}(\mathrm{d})$ & 3.89 \\
\hline & & $\mathrm{C} 1 \mathrm{H}$ & 4.65 \\
\hline 15 & Creatine & $\mathrm{CH}_{3}$ & 3.03 \\
\hline & & $\mathrm{CH}_{2}$ & 3.93 \\
\hline 16 & Ascorbic acid & $-\mathrm{CHOH}-$ & 4.02 \\
\hline & & $\mathrm{C} 4 \mathrm{H}$ & 4.52 \\
\hline 17 & Succinic acid & $\left(\alpha, \beta \mathrm{CH}_{2}\right)$ & 2.40 \\
\hline 18 & Adrenaline & $\mathrm{CH}_{3}-\mathrm{NH}$ & 2.75 \\
\hline & & $\mathrm{C} 4 \mathrm{H}$ & 6.84 \\
\hline & & $\mathrm{C} 3 \mathrm{H}$ & 6.92 \\
\hline & & $\mathrm{C} 6 \mathrm{H}$ & 6.93 \\
\hline
\end{tabular}

Table 1 Continued

\begin{tabular}{|c|c|c|c|}
\hline Numbers & Metabolite & Group & $\begin{array}{c}{ }^{1} \mathbf{H} \text { chemical } \\
\text { shift } \\
\text { (p.p.m.) }\end{array}$ \\
\hline 19 & $\mathrm{~N}$-acetyl aspartate (NAA) & $\begin{array}{l}\mathrm{CH}_{3} \\
\alpha \mathrm{CH}\end{array}$ & $\begin{array}{l}2.04 \\
4.37\end{array}$ \\
\hline 20 & Glutathione & $\begin{array}{l}\mathrm{CH}_{2}-\mathrm{CONH} \\
\mathrm{CH}_{2}-\mathrm{SH} \\
\mathrm{CH}-\mathrm{NH}_{2}\end{array}$ & $\begin{array}{l}2.54 \\
2.95 \\
3.78\end{array}$ \\
\hline 21 & Acetate & $\begin{array}{l}\mathrm{CH}_{3} \\
3 \mathrm{CH}_{2}\end{array}$ & $\begin{array}{l}1.92 \\
1.90\end{array}$ \\
\hline 22 & $\begin{array}{l}\gamma \text {-Aminobutyric acid } \\
\text { (GABA) }\end{array}$ & $\begin{array}{l}4 \mathrm{CH}_{2} \\
2 \mathrm{CH}_{2}\end{array}$ & $\begin{array}{l}2.28 \\
3.01\end{array}$ \\
\hline 23 & Noradrenaline & $\begin{array}{l}\mathrm{C} 4 \mathrm{H} \\
\mathrm{C} 3 \mathrm{H} \\
\mathrm{C} 6 \mathrm{H}\end{array}$ & $\begin{array}{l}6.84 \\
6.92 \\
6.93\end{array}$ \\
\hline 24 & Ethanolamine & $\begin{array}{l}-\mathrm{CH}_{2}-\mathrm{NH}_{3}{ }^{+} \\
\mathrm{CH}_{2} \mathrm{OH}\end{array}$ & $\begin{array}{l}3.13 \\
3.82\end{array}$ \\
\hline $25 a$ & Fatty acids (a) & $\begin{array}{l}\mathrm{CH}_{3} \\
(2) \mathrm{CH}_{2} \\
(1) \mathrm{CH}_{2}\end{array}$ & $\begin{array}{l}0.90 \\
1.29 \\
1.31\end{array}$ \\
\hline $25 b$ & Fatty acids (b) & $\begin{array}{l}(2) \mathrm{CH}_{2} \\
\mathrm{CH}_{2} \\
(2) \mathrm{CH} \\
(1) \mathrm{CH}\end{array}$ & $\begin{array}{l}2.03 \\
2.80 \\
5.33 \\
5.33\end{array}$ \\
\hline $\begin{array}{l}25 a, b \\
25 c\end{array}$ & $\begin{array}{l}\text { Fatty acids (a) and (b) } \\
\text { Fatty acids (c) }\end{array}$ & $\begin{array}{l}\text { (n) } \mathrm{CH}_{2} \\
(2) \mathrm{CH}_{2}\end{array}$ & $\begin{array}{l}1.29 \\
1.60\end{array}$ \\
\hline
\end{tabular}

Spectra were referenced by setting the lactate doublet chemical shift to 1.33 p.p.m. Metabolites were assigned using standard metabolite chemical shift tables available in the literature (Martinez-Bisbal et al. 2004, Wishart et al. 2007).

significantly higher in PCC samples than in the normal medullary tissue samples $(P=0.04)$. Adrenaline was moderately more abundant in PCC samples than in the normal tissue samples, without, however, reaching statistical significance.

In patients with VHL disease-related PCCs, only noradrenaline was detected by HRMAS NMR spectroscopy. MEN2- and NF1-related PCC samples showed an elevation of the levels of both adrenaline and noradrenaline (Table 2).

\section{ACCs vs PCCs}

Twelve ACC and 20 PCC samples were included in the analysis. A two-component PLS-DA based on VIP metabolites (Fig. 3) was characterized by a good representation of the $Y$ data $\left(R^{2} Y=0.8\right)$ and a good cumulative confidence criterion of prediction $\left(Q^{2}=0.6\right)$. Statistically significant differences between ACC and PCC samples were found in 14 of the 24 metabolites identified. A higher abundance of adrenaline, noradrenaline, aspartate, scyllo-inositol, GABA, myo-inositol, and ascorbic acid was found to be a significant discriminator of PCCs. On the other hand, ACC

Published by Bioscientifica Ltd. 

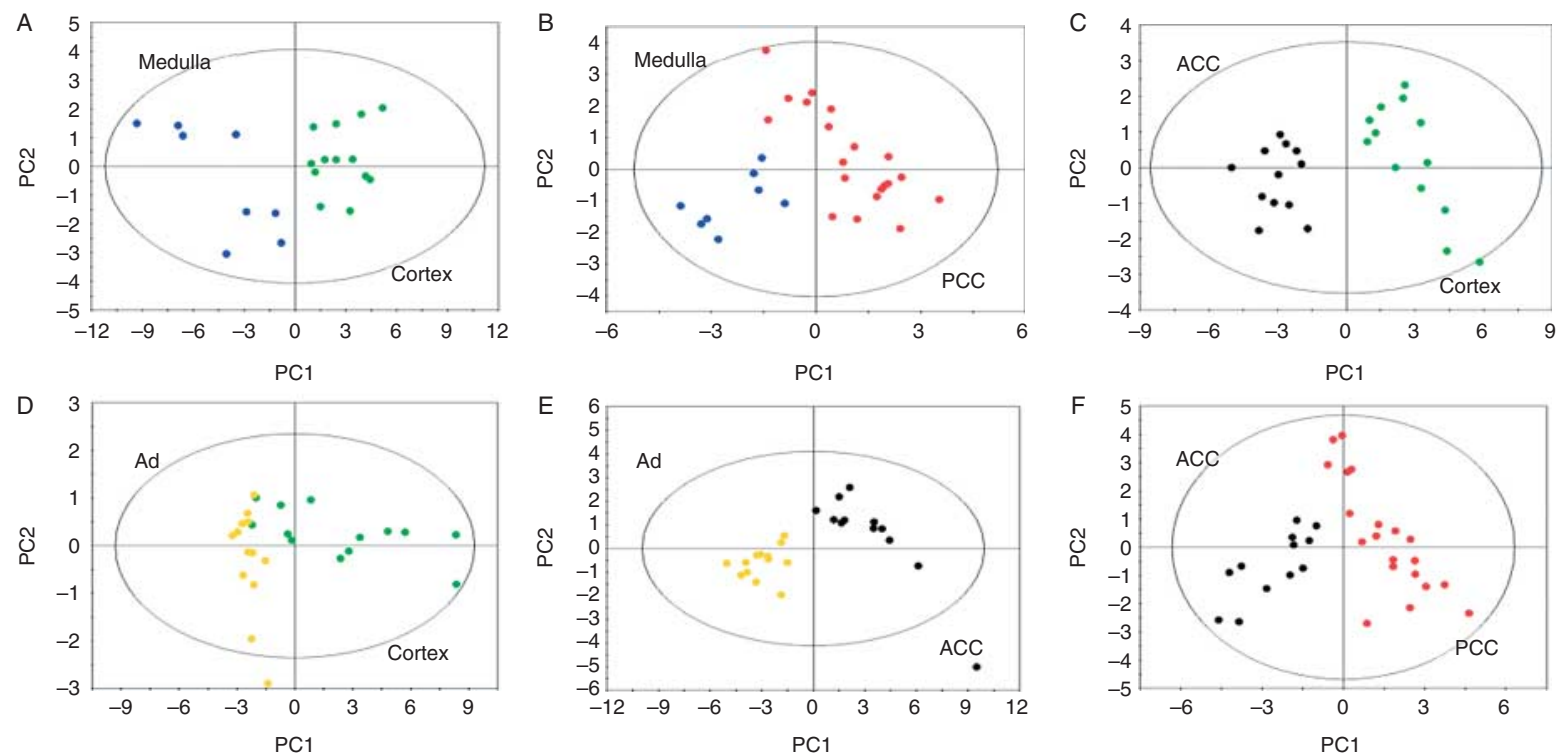

Figure 3

Results of PLS-DA models built according to histological classification: (A) normal adrenal cortex vs normal adrenal medulla, (B) normal adrenal

samples contained a larger amount of glycine, alanine, taurine, creatine, ethanolamine, total choline-containing compounds, and FA (b).

\section{Discussion}

In this study, we analyzed 66 tissue samples of normal and pathological adrenal tissues of adult human subjects by means of HRMAS NMR spectroscopy. The first objective was to characterize the global metabolic profile differentiating normal adrenal cortex from medulla. Afterwards, the biochemical pattern of healthy tissue was compared with that of pathological tissue of the same embryological origin. Finally, the differences between ACCs and both Ads and PCCs were investigated. To the best of our knowledge, no previous study has reported the metabolic fingerprint of the normal adult human adrenal gland and adrenal cortical pathologies such as Ads and ACCs.

The visual comparison of spectra obtained from the cortical tissue samples demonstrated a significant similarity between Ad and normal adrenal cortical tissue samples (Fig. 1), afterwards confirmed by the results of a multivariate analysis. PLS-DA scatter plots evidenced a continuum-like distribution of Ad and normal adrenal cortical tissue samples. Inversely, despite the common embryological origin, ACC samples clearly represented a detached group, reflecting the substantial malignant properties of ACCs. Interestingly, other authors (Rechache medulla vs PCC, (C) normal adrenal cortex vs ACC, (D) normal adrenal cortex vs $\mathrm{Ad}$, (E) ACC vs Ad, and (F) ACC vs PCC.

et al. 2012) who have conducted genome-wide DNA methylation profiling of adrenocortical tumor and normal adrenal cortical tissue samples have recently reported similar PCA results. Moreover, in a recent article by the same team, Jain et al. (2012) proposed a working model of the molecular pathogenesis of ACCs showing a malignancy progression from normal cortex to ACCs through cortical hyperplasia and Ads.

Predictably, when compared with the normal adrenal cortical samples, ACC samples exhibited the typical stigmata of neoplastic tissue. The metabolic fingerprint of ACC samples was characterized by the general metabolic markers of malignancy such as cholinecontaining compounds, which are linked to increased phospholipid turnover. Biochemical markers representative of anaerobic processes and increased glycolytic activity such as lactate levels were also present. The abundance of amino acid resonance peaks suggested an increase in amino acid production via nonoxidative pathways. The increased rate of protein degradation related to cell death, which is particularly evident in large and necrotic tumors, or the deregulation of the Krebs cycle may explain the altered amino acid concentration observed in ACC samples.

Significantly higher levels of lactate, acetate, and total choline-containing compounds play a major role in the differentiation of ACCs from Ads. Moreover, the large FA content of ACC samples contributed to the cluster

Published by Bioscientifica Ltd. 

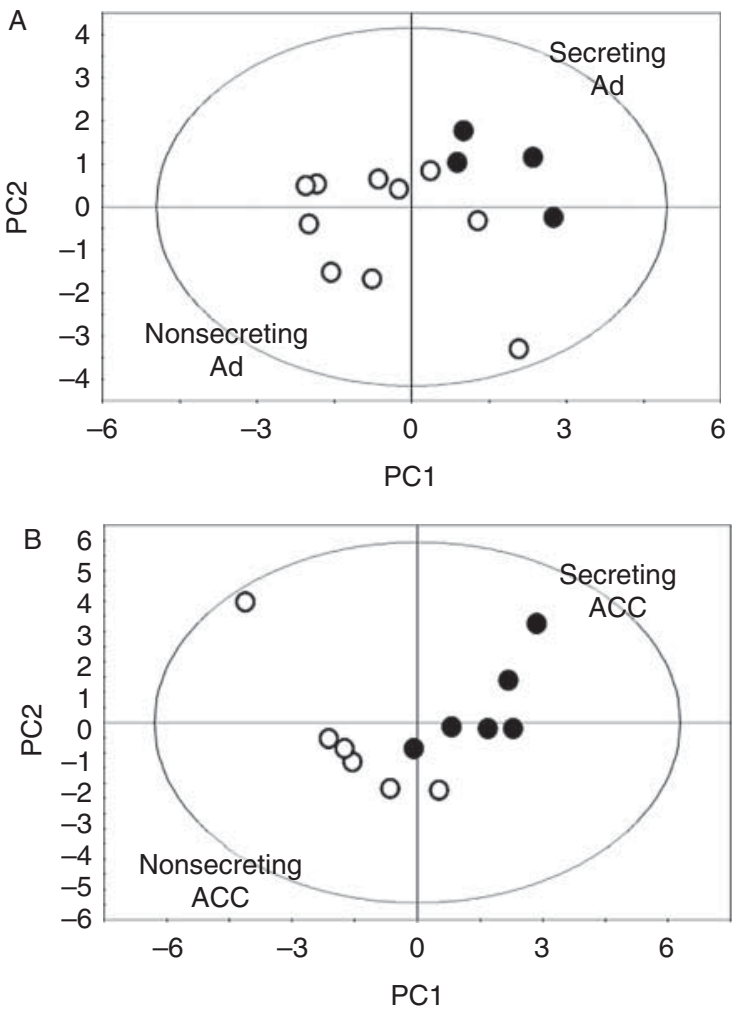

Figure 4

Results of PLS-DA models built respectively from Ad (A) and ACC (B) samples according to tumoral secreting properties. Both classes of PLS-DA models show a separation between secreting and nonsecreting lesions.

identification of ACCs. The esterification of acetate to form acetyl $\mathrm{CoA}$ as a major precursor in $\beta$-oxidation for FA synthesis is believed to be the main mechanism of acetate incorporation in tumors. Nevertheless, alternative biochemical pathways of acetate intake or accumulation may include the Krebs cycle and the synthesis of cholesterol through citrate.

According to the secreting properties, good results were obtained by PLS-DA models built from both ACC and Ad samples. Unfortunately, when considering the natural history of ACCs, patients with aggressive ACCs (metastatic spread at diagnosis or within 1 year of surgery) were not successfully separated by PLS-DA from patients without metastatic ACCs at diagnosis and during the first 5 years of postsurgical follow-up. However, both the small size and the asymmetry of groups are limiting factors potentially influencing the final results. Further investigations with a larger population are necessary to assess a potential metabolic fingerprint specific for a poor prognosis.

To date, only one recent paper mainly focused on PCCs and paragangliomas (Rao et al. 2013) is available concerning the application of NMR spectroscopy for adrenal pathology investigation. Compared with Rao's study, in which liquid NMR spectroscopy was used to analyze homogenized and centrifuged tissue preparations, we studied intact tissue samples using HRMAS NMR spectroscopy. While the inferior sensitivity compared with that of the liquid-state NMR spectroscopy may be a disadvantage, HRMAS NMR spectroscopy allows for a good spectral quality, avoiding laborious procedures for tissue preparation prior to the analysis. Moreover, the tissue sample can be stored again after the acquisition of spectra and is therefore available for pathological analysis when a discrepancy arises between the metabolic and histopathological data of the mirror sample. In Rao's work, the relationships between genotype-specific differences in mitochondrial function and catecholamine content in paragangliomas (PGLs) have been established. These authors also demonstrated for the first time the feasibility of detecting catecholamines by NMR spectroscopy in PCC and paraganglioma samples, confirming our previous findings obtained from the analysis of normal adrenal medullary tissue samples (Imperiale et al. 2011).

Of the 14 sporadic PCC samples analyzed, 12 exhibited predominant or exclusive noradrenaline secretion. In sporadic PCC samples, HRMAS NMR spectroscopy revealed a greater amount of noradrenaline than of adrenaline. In contrast, in the normal medullary tissue samples, adrenaline was more abundant than noradrenaline. As is well known, the synthesis of adrenaline depends on the presence of phenylethanolamine- $N$-methyltransferase (PNMT). The levels of PNMT mRNA have been found to be lower in PCC samples than in the normal medulla (Lehnert 1998). This disparity is probably responsible for the difference in catecholamine content between tumors and normal adrenal medulla, leading to higher noradrenaline secretion in PCC samples examined in the present study. Unfortunately, the data concerning PNMT tumor activity in the PCC samples examined are not available for further correlations.

In patients with hereditary PCCs, the results of HRMAS NMR investigation matched the biological findings. MEN2- and NF1-related PCC samples exhibited the presence of both adrenaline and noradrenaline. In the VHL disease-related PCC samples, only noradrenaline was detected by HRMAS NMR spectroscopy. The low noradrenaline value measured in the VHL disease-related PCC samples contrasts with the high catecholamine production and the elevated rate constants of catecholamine secretion in this PCC genotype. The small quantity of starting material for the NMR analysis may be a potential bias in the assessment of the amount of noradrenaline.

Published by Bioscientifica Ltd. 

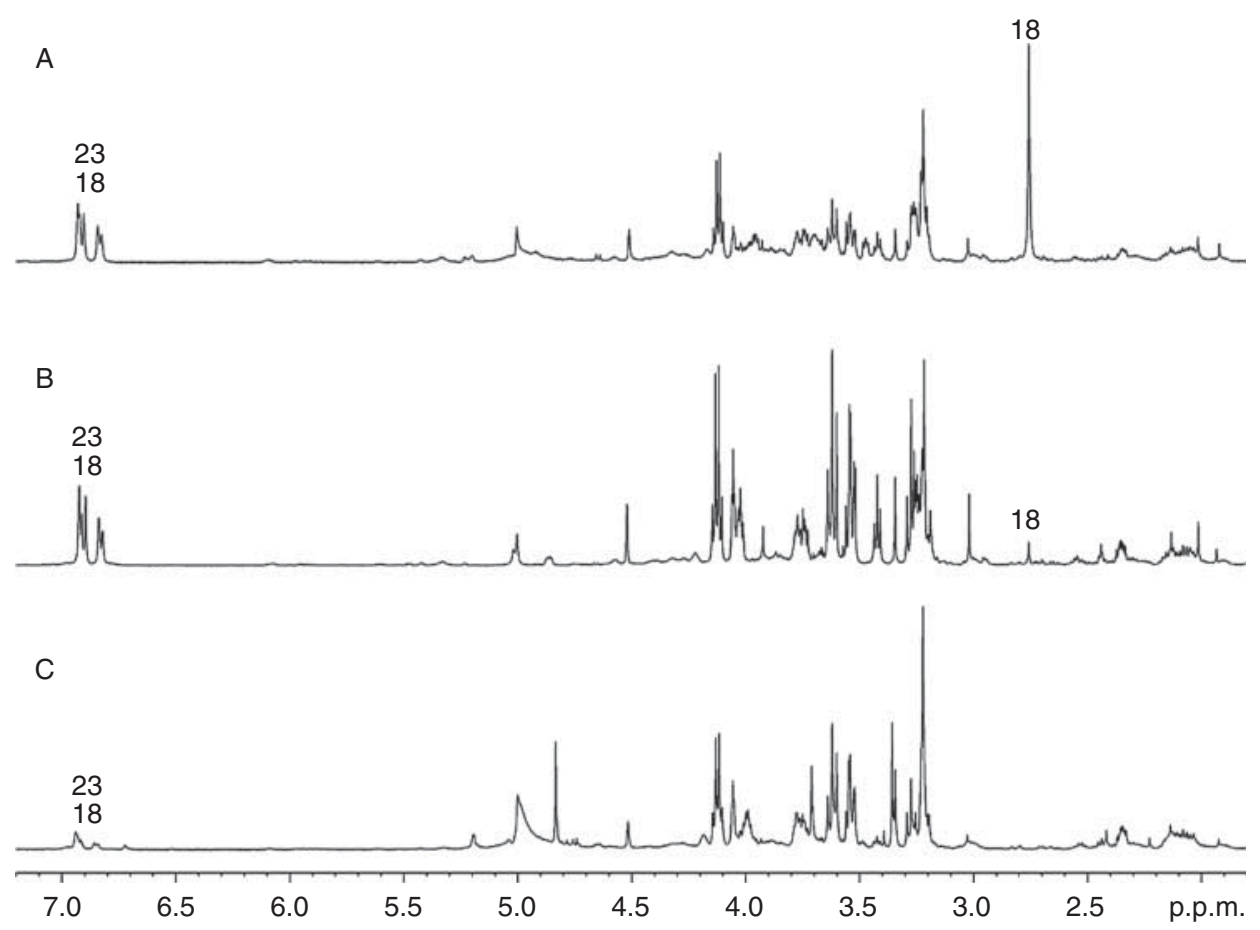

\section{Figure 5}

One-dimensional ${ }^{1} \mathrm{H}$ CPMG HRMAS spectra obtained from three sporadic PCC samples with different catecholamine-secreting patterns:

(A) predominant adrenaline secretion, (B) predominant noradrenaline secretion, and (C) exclusive noradrenaline secretion. The intensity of each spectrum was normalized with respect to the weight of the tissue sample. The numbers refer to the metabolites listed in Table 1.

early 1980s, Hatanaka et al. (1980) described a clonal cell line (PC 12) established from a rat PCC model able to synthesize GABA together with catecholamine and acetylcholine.

Ascorbic acid is critical in the biochemical cascade of catecholamine production (Lehnert 1998). In the present series, ascorbic acid was identified as a significant discriminator of PCCs than of the normal medulla and ACCs. In 1977, a clonal line of rat PCC cells was used as esting a role in PCC pathophysiology. Interestingly, in the

Table 2 Catecholamine quantification results obtained from the HRMAS NMR analysis of eight normal medullary tissue and 20 PCC samples

\begin{tabular}{lc}
\hline & $\begin{array}{c}\text { Number of } \\
\text { samples }\end{array}$ \\
\hline Normal medulla & 8 \\
Sporadic PCC & 14 \\
VHL disease-related PCC & 1 \\
NF1-related PCC & 1 \\
MEN2-related PCC & 1 \\
& 1 \\
\hline
\end{tabular}

\begin{tabular}{c}
\hline $\begin{array}{c}\text { NA } \\
(\mathrm{nmol} / \mathrm{mg})\end{array}$ \\
\hline $0.6(0-1.8)^{\mathrm{a}}$ \\
$2.4(0-11.6)^{\mathrm{a}}$ \\
1 \\
0.4 \\
2.8 \\
1.6 \\
5.8 \\
0.8 \\
\hline
\end{tabular}

\begin{tabular}{c}
\hline $\begin{array}{c}\text { Adrenaline } \\
(\mathrm{nmol} / \mathrm{mg})\end{array}$ \\
\hline $1.6(0.7-4.4)^{\mathrm{a}}$ \\
$1.8(0-5.3)^{\mathrm{a}}$ \\
$\mathrm{ND}$ \\
$\mathrm{ND}$ \\
2.1 \\
1.1 \\
2.3 \\
3.9
\end{tabular}

NA, noradrenaline; ND, undetectable. ${ }^{a}$ Median (range).

http://erc.endocrinology-journals.org DOI: $10.1530 /$ ERC-13-0232
(C) 2013 Society for Endocrinology Printed in Great Britain
Published by Bioscientifica Ltd. 
a model of noradrenergic tissue to study ascorbic acid transport (Spector \& Greene 1977). In these cells, ${ }^{14} \mathrm{C}$-ascorbic acid was concentrated by an energydependent transport system. Moreover, the optimal production of noradrenaline required ascorbate in the medium. In our 20 PCC samples, ascorbic acid was significantly correlated (Spearman's correlation test, $P<0.05)$ to the amount of noradrenaline $(R=0.56)$. The level of noradrenaline in PCC samples could also be biased from the lack of PNMT. However, the correlation existing also between ascorbic acid and adrenaline amounts $(R=0.55)$ and the sum of noradrenaline plus adrenaline amounts $(R=0.64)$ underlines the role played by ascorbate in catecholamine biosynthetic pathway.

The 3,4-dihydroxybenzene group, common to both adrenaline and noradrenaline, generates a clear signal between 6.8 and 6.9 p.p.m. This signal, unaffected by any significant pollution, is hence easy to recognize and quantify. According to these considerations, the 3,4dihydroxybenzene group resonance assumes a diagnostic significance and may have an impact on clinical practice. Interesting results were reported on this topic by Kim et al. (2009), who used in vivo MRS to describe a signal at 6.8 p.p.m. in PCC samples probably representing catecholamines not observed in cortical Ad samples. Indeed, further developments of in vivo magnetic resonance spectroscopy (MRS) focusing on catecholamine spectral regions could be an interesting and useful axis of clinical research in patients with atypical adrenal masses that are challenging to characterize by preoperative investigations.

Despite these interesting results, this study has the inherent limitations of any retrospective observational case series including a relatively limited number of patients because it was focused on a rare condition. Consequently, the small number of samples makes this study a preliminary investigation. In addition, malignant PCCs, which are the most clinically important tumors with a particularly poor prognosis, are not adequately represented. Nevertheless, this study represents one of the first applications of metabolomics to adrenal pathophysiology and it is the largest study to report HRMAS data related to the adrenal cortex and adrenal cortical tumors, laying the foundations for future, more complex investigations also including data from molecular biology and other omics procedures.

\section{Declaration of interest}

The authors declare that there is no conflict of interest that could be perceived as prejudicing the impartiality of the research reported.

\section{Funding}

This work is part of the CARMeN project and was supported by grants from Région Alsace, Oséo, Communauté Urbaine de Strasbourg, Conseil Départemental du Bas-Rhin, Bruker BioSpin, University of Strasbourg, and Strasbourg University Hospital.

\section{Author contribution statement}

A I wrote the manuscript and was responsible for study design, data analysis, bibliographic research, and manuscript review; F-M M was responsible for HRMAS NMR data acquisition, spectral analysis, and manuscript review; K E was responsible for experimental design, spectral analysis, and manuscript review; N R was involved in patient biological exploration and manuscript review; $\mathrm{M} P$ had responsibility for experimental design and manuscript review; J-P B conducted the histopathological analysis; B G was involved in patient clinical management and manuscript review; P B was responsible for patient surgical management and manuscript review; and I-J N was involved in experimental design, data analysis, and manuscript review. All the authors read and approved the final manuscript.

\section{Acknowledgements}

The Tumor Bio-bank (Centre de Ressources Biologiques) personnel of the Strasbourg University Hospital are gratefully acknowledged for their technical assistance.

\section{References}

Beckonert O, Coen M, Keun HC, Wang Y, Ebbels TM, Holmes E, Lindon JC \& Nicholson JK 2010 High-resolution magic-angle-spinning NMR spectroscopy for metabolic profiling of intact tissues. Nature Protocols 5 1019-1032. (doi:10.1038/nprot.2010.45)

Claudino WM, Goncalves PH, di Leo A, Philip PA \& Sarkar FH 2012 Metabolomics in cancer: a bench-to-bedside intersection. Critical Reviews in Oncology/Hematology 84 1-7. (doi:10.1016/j.critrevonc. 2012. 02.009)

Ebbels T \& Cavill R 2009 Bioinformatic methods in NMR-based metabolic profiling. Progress in Nuclear Magnetic Resonance Spectroscopy 55 361-374. (doi:10.1016/j.pnmrs.2009.07.003)

Elbayed K, Dillmann B, Raya J, Piotto M \& Engelke F 2005 Field modulation effects induced by sample spinning: application to high-resolution magic angle spinning NMR. Journal of Magnetic Resonance 174 2-26. (doi:10.1016/j.jmr.2004.11.017)

Griffin JL \& Shockor JP 2004 Metabolic profiles of cancer cells. Nature Reviews. Cancer 4 551-561. (doi:10.1038/nrc1390)

Hatanaka H, Tanaka M \& Amano T 1980 A clonal rat pheochromocytoma cell line possesses synthesizing ability of $\gamma$-aminobutyric acid together with catecholamine and acetylcholine. Brain Research 183 490-493. (doi:10.1016/0006-8993(80)90487-4)

Imperiale A, Elbayed K, Moussallieh FM, Neuville A, Piotto M, Bellocq JP, Lutz P \& Namer IJ 2011 Metabolomic pattern of childhood neuroblastoma obtained by ${ }^{1} \mathrm{H}$-high-resolution magic angle spinning (HRMAS) NMR spectroscopy. Pediatric Blood \& Cancer 56 24-34. (doi:10.1002/pbc.22668)

Jain M, Rechache N \& Kebebew E 2012 Molecular markers of adrenocortical tumors. Journal of Surgical Oncology 106 549-556. (doi:10.1002/jso. 23119)

Kim S, Salibi N, Hardie AD, Xu J, Lim RP, lee VS \& Taouli B 2009 Characterization of adrenal pheochromocytoma using respiratorytriggered proton MR spectroscopy: initial experience. AJR. American Journal of Roentgenology 192 450-454. (doi:10.2214/AJR.07.4027) 
Korevaar TI \& Grossman AB 2011 Pheochromocytomas and paragangliomas: assessment of malignant potential. Endocrine 40 354-365. (doi:10.1007/s12020-011-9545-3)

Lehnert H 1998 Regulation of catecholamine synthesizing enzyme gene expression in human pheochromocytoma. European Journal of Endocrinology 138 363-367. (doi:10.1530/eje.0.1380363)

Lloyd RV 2011 Adrenal cortical tumors, pheochromocytomas and paragangliomas. Modern Pathology 24 S58-S65. (doi:10.1038/ modpathol.2010.126)

Lombardi CP, Raffaelli M, Pani G, Maffione A, Princi P, Traini E, Galeotti T, Rossi ED, Fadda G \& Bellantone R 2006 Gene expression profiling of adrenal cortical tumors by cDNA macroarray analysis. Results of a preliminary study. Biomedicine \& Pharmacotherapy 60 186-190. (doi:10.1016/j.biopha.2006.03.006)

Martinez-Bisbal MC, Marti-Bonmati L, Piquer J, Revert A, Ferrer P, Llacer JL, Piotto M, Assemat O \& Celda B 2004 1H and 13C HR-MAS spectroscopy of intact biopsy samples ex vivo and in vivo 1H MRS study of human high grade gliomas. NMR in Biomedicine 17 191-205. (doi:10.1002/ nbm.888)

McNicol AM 2011 Update on tumours of the adrenal cortex, phaeochromocytoma and extra-adrenal paraganglioma. Histopathology $\mathbf{5 8}$ 155-168. (doi:10.1111/j.1365-2559.2010.03613.x)

Nicholson JK \& Wilson ID 2003 Understanding 'global' systems biology; metabonomics and the continuum of metabolism. Nature Reviews. Drug Discovery 2 668-676. (doi:10.1038/nrd1157)

O'Connell TM 2012 Recent advances in metabolomics in oncology. Bioanalysis 4 431-451. (doi:10.4155/bio.11.326)

Papotti M, Libé R, Durengon E, Volante M, Bertherat J \& Tissier F 2011 The Weiss score and beyond - histopathology for adrenocortical carcinoma. Hormones \& Cancer 2 333-340. (doi:10.1007/s12672-011-0088-0)

Peet AC, McConville C, Wilson M, Levine BA, Reed M, Dyer SA, Edwards EC, Strachan MC, McMullan DJ, Wilkes TM et al. 2007 1H MRS identifies specific metabolite profiles associated with MYCN-amplified and non-amplified tumour subtypes of neuroblastoma cell lines. NMR in Biomedicine 20 692-700. (doi:10.1002/nbm.1181)

Piotto M, Bourdonneau M, Furrer J, Bianco A, Raya J \& Elbayed K 2001 Destruction of magnetization during TOCSY experiments performed under magic angle spinning: effect of radial B1 inhomogeneities. Journal of Magnetic Resonance 149 114-118. (doi:10.1006/jmre.2001.2287)

Piotto M, Moussallieh FM, Dillmann B, Imperiale A, Neuville A, Brigand C, Bellocq JP, Elbayed K \& Namer IJ 2009 Metabolic characterization of primary human colorectal cancers using high resolution magic angle spinning $1 \mathrm{H}$ magnetic resonance spectroscopy. Metabolomics 5 292-301. (doi:10.1007/s11306-008-0151-1)
Piotto M, Moussallieh FM, Imperiale A, Benahmed MA, Detour J, Bellocq JP, Namer IJ \& Elbayed K 2012 Reproducible sample preparation and spectrum acquisition techniques for metabolic profiling of human tissues by proton high-resolution magic angle spinning nuclear magnetic resonance. In Methodologies for Metabolomics: Experimental Strategies and Techniques, pp 496-524. Ed P Lutz. UK: Cambridge University Press.

Rao JU, Engelke U, Rodenburg R, Wevers R, Pacak K, Eisenhofer G, Qin N, Kuster B, Goudswaard A, Lenders JW et al. 2013 Genotype-specific abnormalities in mitochondrial function associate with distinct profiles of energy metabolism and catecholamine content in pheochromocytoma and paraganglioma. Clinical Cancer Research 30 3787-3795. (doi:10.1158/1078-0432.CCR-12-3922)

Rechache NS, Wang I, Stevenson HS, Killian JK, Edelman DC, Merino M, Zhang L, Nilubol N, Stratakis CA, Meltzer PS et al. 2012 DNA methylation profiling identifies global methylation differences and markers of adrenocortical tumors. Journal of Clinical Endocrinology and Metabolism 97 E1004-E1013. (doi:10.1210/jc.2011-3298)

Roman S 2006 Adrenocortical carcinoma. Current Opinion in Oncology 18 36-42. (doi:10.1097/01.cco.0000198976.43992.14)

Sitter B, Bathen TF, Tessem MB \& Gribbestad IS 2009 High-resolution magic angle spinning (HR MAS) MR spectroscopy in metabolic characterization of human cancer. Progress in Nuclear Magnetic Resonance Spectroscopy 54 239-254. (doi:10.1016/j.pnmrs.2008.10.001)

Spector R \& Greene LA 1977 Ascorbic acid transport by a clonal line of pheochromocytoma cells. Brain Research 136 131-140. (doi:10.1016/ 0006-8993(77)90137-8)

Stratakis CA 2003 Genetics of adrenocortical tumors: gatekeepers, landscapers and conductors in symphony. Trends in Endocrinology and Metabolism 14 404-410. (doi:10.1016/j.tem.2003.08.005)

Stratakis CA 2005 Applications of genomic medicine in endocrinology and post-genomic endocrine research. Hormones 4 38-44.

Weiss LM, Medeiros LJ \& Vickery AL Jr 1989 Pathologic features of prognostic significance in adrenocortical carcinoma. American Journal of Surgical Pathology 13 202-206. (doi:10.1097/00000478198903000-00004)

Wilson M, Davies NP, Brundler MA, McConville C, Grundy RG \& Peet AC 2009 High resolution magic angle spinning $1 \mathrm{H}$ NMR of childhood brain and nervous system tumours. Molecular Cancer 8 6-17. (doi:10.1186/1476-4598-8-6)

Wishart DS, Tzur D, Knox C, Eisner R, Chi Guo A, Young N, Cheng D, Jewell K, Arndt D, Sawhney S et al. 2007 HMDB: Human Metabolome Database. Nucleic Acids Research 35 D521-D526. (doi:10.1093/nar/gk1923)

Young WF 2007 Incidentally discovered adrenal mass. New England Journal of Medicine 356 601-610. (doi:10.1056/NEJMcp065470)

Received in final form 25 July 2013

Accepted 6 August 2013

Made available online as an Accepted Preprint

6 August 2013 http://erc.endocrinology-journals.org

DOI: $10.1530 / E R C-13-0232$
(C) 2013 Society for Endocrinology Printed in Great Britain
Published by Bioscientifica Ltd. 